\title{
An overview of the basic science of concussion and subconcussion: where we are and where we are going
}

\author{
Matthew L. Dashnaw, M.D., Pharm.D., ${ }^{1}$ Anthony L. Petraglia, M.D., ${ }^{1}$ \\ and Julian E. Bailes, M.D.² \\ ${ }^{1}$ Department of Neurosurgery, University of Rochester Medical Center, Rochester, New York; and \\ ${ }^{2}$ Department of Neurosurgery, NorthShore University Health System, University of Chicago Pritzker School \\ of Medicine, Evanston, Illinois
}

\begin{abstract}
There has been a growing interest in the diagnosis and management of mild traumatic brain injury (TBI), or concussion. Repetitive concussion and subconcussion have been linked to a spectrum of neurological sequelae, including postconcussion syndrome, chronic traumatic encephalopathy, mild cognitive impairment, and dementia pugilistica. A more common risk than chronic traumatic encephalopathy is the season-ending or career-ending effects of concussion or its mismanagement. To effectively prevent and treat the sequelae of concussion, it will be important to understand the basic processes involved. Reviewed in this paper are the forces behind the primary phase of injury in mild TBI, as well as the immediate and delayed cellular events responsible for the secondary phase of injury leading to neuronal dysfunction and possible cell death. Advanced neuroimaging sequences have recently been developed that have the potential to increase the sensitivity of standard MRI to detect both structural and functional abnormalities associated with concussion, and have provided further insight into the potential underlying pathophysiology. Also discussed are the potential long-term effects of repetitive mild TBI, particularly chronic traumatic encephalopathy. Much of the data regarding this syndrome is limited to postmortem analyses, and at present there is no animal model of chronic traumatic encephalopathy described in the literature. As this arena of TBI research continues to evolve, it will be imperative to appropriately model concussive and even subconcussive injuries in an attempt to understand, prevent, and treat the associated chronic neurodegenerative sequelae.

(http://thejns.org/doi/abs/10.3171/2012.10.FOCUS12284)
\end{abstract}

KEY WORDS • concussion • chronic traumatic encephalopathy

\section{subconcussion •}

- pathophysiology
$\mathrm{T}$ There has been a growing interest in the diagnosis and management of mild TBI, or concussion. With new research initiatives and skyrocketing levels of public awareness, society has gained a better understanding of concussion and mild TBI, while we as a medical community have learned that we have a long way to go. Repetitive concussion and subconcussion have been linked to significant morbidity and death. This paper will review the forces behind the primary phase of injury, as well as the immediate and delayed cellular events responsible for the secondary phase of injury leading to neuronal dysfunction and possible cell death associated with mild TBI. While the cascade of events within the cells and neurons of the CNS are profound, the role of both acute and chronic inflammation is also important to acknowledge.

There has also been increased public awareness regarding the long-term sequelae of repetitive mild head

Abbreviations used in this paper: $\mathrm{BBB}=$ blood-brain barrier; $\mathrm{CBF}=$ cerebral blood flow; $\mathrm{TBI}=$ traumatic brain injury. injuries or even subconcussive injuries. We will review some of the pertinent work on repetitive mild TBI and possible implications in the development of neurodegenerative disease, particularly chronic traumatic encephalopathy. More frequent than posttraumatic chronic neurodegenerative disease, however, is the increased risk for season-ending or career-ending effects of concussion or its mismanagement. Paramount to effective prevention, diagnosis, and management of the vast number of athletes, soldiers, and patients affected by the sequelae of mild TBI is a sound understanding of the forces behind the primary injury and the pathophysiological cascade of events that ensue following the primary injury, when the brain falls victim to a concussive event or multiple events over time.

\section{The Biophysics of Head Impact}

Traumatic brain injury is traditionally believed to involve both primary and secondary injury phases. The primary injury is represented by the moment of impact, 
resulting from the translation of kinetic energy and force vectors in either a linear acceleration-deceleration mechanism, through a rotational mechanism, or a combination of both. Newton's Second Law of Motion enables the visualization of how forces in head impacts result in head, and consequently brain, acceleration:

force $=$ mass $\times$ acceleration (Newton's Second Law)

While this equation quantifies the linear forces that come into play with head injury, in instances of rotational force or torque, we have the equation:

torque $=$ moment of inertia $\times$ angular acceleration

In understanding just these two basic physics concepts, a great deal can be appreciated in concussion biomechanics, as linear and angular brain accelerations have been shown to be the most predictive variables of head injury. Most cases of head injury involve both linear and angular forces.

When considering the laws of conservation of energy, the sum of the kinetic energies of the struck patient and the striking object is equal to the total linear and angular energy imparted to the head, plus that energy dissipated from the head. A review of the equation for kinetic energy reveals the importance of velocity on the impacted neural structures:

kinetic energy $=1 / 2$ mass $\times(\text { velocity })^{2}$

When we consider modern day athletics, today's athletes are not only larger (increased mass), but more importantly, the velocities at which impacts occur is also substantially increased. With squaring of the velocity of impact in the kinetic energy rotation, the resulting increase in kinetic energy, and therefore imparted forces, is profound.

Early studies on the biophysics of concussion were performed in nonhuman primate models of concussion. . $^{2,70,71,85,89,107}$ Analyses of the data at that time led investigators to believe that approximately half of the potential for concussion during impact to the unprotected movable head was related to head rotation, with the remaining brain injury potential of the blow being related to the contact phenomena of the impact. ${ }^{71}$ Although the biodynamics in these primate models were likely more similar to human concussion, such studies were limited to small group size. With regard to our modern day athletes and the biophysics of head injury, the mandatory use of helmets in American football has allowed for the systematic analysis of injury biomechanics and real-time measurements of forces, velocities, and accelerations of head impacts by implanted telemetry devices. ${ }^{33}$ The US National Football League has organized study of detailed computerized video analysis of actual game film in 182 concussive and subconcussive hits that occurred between 1996 and $2001 .^{73}$ Using these data, investigators were than able to remodel these impacts in the laboratory setting by incorporating crash test dummies. The results of the investigation demonstrated that the highest strain forces were imparted to the region corresponding to the deep midbrain level, occurring 10 milliseconds following the impact. It was further inferred that these forces imparted to the mesencephalon, corpus callosum, and fornix may be responsible for concussion symptoms such as loss of consciousness, amnesia, and cognitive dysfunc-
M. L. Dashnaw, A. L. Petraglia, and J. E. Bailes

tion. ${ }^{73}$ Even in less severe impacts, not resulting in loss of consciousness, there appeared to be significant forces transmitted to deep midbrain and brainstem structures, implying injury in subconcussive impacts as well. ${ }^{73}$

Since that time there has been an explosion in research performed investigating the biomechanics and biophysics of mild TBI. 5,11,12,15,27,28,60,73,82,87,100 Biophysics data gathered through football helmet accelerometer studies at the youth, high school, and college level have shown that players may experience a wide range of head impacts, as well as magnitudes of force. This research has also suggested that it may more likely be that the cumulative number of head impacts best correlates with the potential for concussion occurrence or chronic effects. The athlete's risk of experiencing long-standing effects of repetitive blows is likely measured as a cumulative dose over a lifetime, and could include factors such as age at exposure, type and magnitude of exposure, recovery periods as well as differential rates of recovery, genotype, and others.

Among the numerous factors in understanding the increased risk of head trauma in contact and collision sports, the velocities of the collisions are of particular importance. In actuality it is the change in velocity, through acceleration-deceleration, which relates to the energy transmitted to the player's body and brain. In essence, the brain is suspended within fluid-filled space with a certain degree of movement, relatively tethered at discreet intervals, and housed within a rigid container. The brain is able to accelerate with this reserve volume (filled with CSF) through which the brain can accelerate and collide with the skull. This movement has been referred to as "brain slosh" due to the semisolid properties of neural tissue and its surrounding stromal cytoarchitecture. ${ }^{96}$

\section{Pathophysiology Underlying Secondary Injury in Mild TBI}

Secondary injury is classically described as the indirect result of the trauma and its subsequent pathophysiological processes. These pathophysiological processes involve both immediate and delayed cellular events including ultrastructural damage, ionic shifts, and neurotransmission effects, among other events. ${ }^{64}$ There are also remarkable effects on cerebral blood flow dynamics and the BBB contributing to the pathophysiology of secondary brain injury.

The forces imparted to the neural structures discussed above are believed to result in shear stress to neurons, thereby resulting in axonal disruption. ${ }^{57}$ Although traumatic axonal injury is best described in more severe models of TBI, it is also believed to play an important role in mild TBI. ${ }^{97}$ Neurofilament compaction has been shown to occur as soon as 5 minutes after injury and lasts for approximately 6 hours. It is believed that this event is caused by phosphorylation, leading to instability. ${ }^{65,68,98}$ Ultimately, the ultrastructural alterations of neurofilaments and microtubules cause focal swellings at the site of injury and interference of axonal transport. ${ }^{54,83}$ Eventually, blebbing of this region occurs, and signs of axonal 
disconnection have been witnessed as early as 4 hours after injury. ${ }^{75}$ It has been reported that this detachment persists for days to weeks in humans. ${ }^{10}$

Returning to the more immediate effects of shear injury to neuronal membranes, dysregulation of protein channels within the neuronal plasmalemma then ensues, resulting in uncontrolled ion flux and neurotransmitter effects. ${ }^{22}$ Specifically, liberation of potassium, certain neurotransmitters and excitatory amino acids occurs, particularly glutamate. ${ }^{21,39}$ Glutamate then acts on several receptors, including $N$-methyl-D-aspartate receptors, causing further depolarization and calcium influx into the neuron. As a result, adenosine triphosphate-dependent pumps are forced to work "on overdrive" to restore ionic homeostasis, which results in a hypermetabolic state beginning approximately 30 minutes after injury. ${ }^{40,108}$ It has also been shown that there is a switch from a hypermetabolic state to a hypometabolic state 5-6 hours later, which can last up to 5 days or longer. ${ }^{7}$ Consequently, more glycolysis and anaerobic respiration occurs, and local extracellular acidosis follows, possibly contributing to further membrane permeability. ${ }^{36}$

Glutamate-mediated accumulation of intracellular calcium ions also results in mitochondrial oxidative dysfunction. ${ }^{47,80,102,105}$ Hovda et al. ${ }^{34}$ showed that cytochrome oxidase, a marker of oxidative function, is downregulated after injury in rodent models up to 10 days after mild TBI. This downregulation likely further potentiates the cascade of adverse events in mild TBI, in which a metabolically hyperactive brain, early in injury, has a hindrance in oxidative functioning. Certainly, this is disadvantageous for a brain in a hypermetabolic state with already reduced adenosine triphosphate, and it is believed that this exacerbates the cascade of events in acute concussion.

\section{Cerebral Blood Flow Dynamics}

In the uninjured brain $\mathrm{CBF}$ is highly regulated, with the ability to rapidly adjust perfusion levels to meet the brain's metabolic needs. In TBI, however, CBF has been shown to be decreased immediately after injury. ${ }^{26,63}$ This was further shown by Yamakami and McIntosh ${ }^{106}$ in a rat model of concussion, in which there was decreased regional $\mathrm{CBF}$ in the perilesional area within 15 minutes and that persisted for at least 2 hours after injury.

A study of human $\mathrm{CBF}$ in 125 patients with severe TBI by Martin et al. ${ }^{50}$ documents 3 phases of blood flow dynamics. Phase I is characterized by an acutely hypoperfused state, lasting for 1 day. Phase II, beginning on the 2nd day, consists of significantly increased CBF. Phase III, which begins on Day 4, is characterized by vasospasm that may last until 15 days after the inciting injury. Angiographic vasospasm has been shown during the time period designated as Phase III in a separate work. ${ }^{99}$ Maugans et al. ${ }^{53}$ studied pediatric patients ages 11 to 15 years old. They examined 12 athletes at 3 time points after injury (within 3 days, at 14 days, and 30 days or greater after concussion), comparing blood flow using phase-contrast angiography. These investigators found a significant reduction in blood flow compared with controls at the first time point, which continued through the final time point (compared with controls). In fact, only $27 \%$ of the participants had returned to within $10 \%$ of control mean $\mathrm{CBF}$ by 2 -week measurements, and only $64 \%$ by the final time point.

\section{Breakdown of the BBB}

The BBB is the highly regulated separation between the intravascular and extravascular content of the CNS. Blood-brain barrier breakdown is well documented in animal models of severe TBI. ${ }^{90}$ Furthermore, a study of patients with postconcussion syndrome demonstrated that $\mathrm{BBB}$ disruption can be observed weeks to months after the original insult. ${ }^{42}$ The events leading to BBB breakdown are likely multiple in nature. The shearing forces of primary injury are believed to damage the BBB endothelium, resulting in increased small vessel permeability and dysregulation. ${ }^{93}$ A metabolic imbalance from ischemic zones of tissue hypoxia likely ensues, potentiating localized BBB destruction. Other mechanisms such as vasospasm, $\mathrm{CBF}$ alterations, irregularities in nitric oxide secretion, and coagulopathy may also contribute early after injury. At time points further from injury, astrocyte dysfunction, inflammation-mediated disturbances, and metabolic disturbances may further contribute to, or prolong, BBB breakdown.

Breakdown of the BBB has several untoward consequences. First and foremost, fluid exudation from BBB breakdown results in brain edema. This edema may result in increased intracranial pressure, and lower cerebral perfusion pressure can ensue with sufficient fluid accumulation. Excitotoxicity from neuronal membrane damage may be further exacerbated by the loss of ionic flux control from BBB breakdown, resulting in extravasation of excitatory amino acids. Similarly, as other ions and molecules equilibrate in the serum and CSF, a neuronal microenvironment develops that creates a predisposition for focal seizure activity. ${ }^{42}$ Numerous in vitro studies of isolated brain slices have demonstrated enhanced cortical excitability, hypersynchronicity, and epileptiform-like activity. . $^{31,84,88}$ These numerous studies provide a possible explanation for the seizure activity noted in animal models of mild head trauma ${ }^{66}$ and in several reports in humans..$^{30,55}$

\section{The Role of Neuroinflammation}

The role of immunoexcitotoxicity is significant in TBI. In the brain, microglia play a key role in the initiation of inflammatory events following injury. ${ }^{20,25,32}$ As microglia become activated, anti- and proinflammatory cytokines, chemokines, nitric oxide, prostaglandins, trophic factors, free radicals, lipid peroxidation products, and excitatory molecules are released into the extraneuronal space within the 1st postinjury hour and may be present for up to 30 days. ${ }^{9,78}$ Some of these chemokines attract peripheral macrophages to the brain to transdifferentiate into microglia and further participate in cytokine release. ${ }^{77,79}$

In normal reactions to a single mild TBI, over time microglia eventually enter a reparative phase composed 
of phagocytic activity to repair any debris and damaged cells, and ultimately return to their resting state. ${ }^{8} \mathrm{With}$ repeated brain injury, microglia may enter a constitutively activated state and become neurodestructive, which may translate into risk for chronic traumatic encephalopathy. ${ }^{8}$

\section{Sequelae of Repetitive Mild TBI}

In the past decade, there has been an increased interest in laboratory research focused on repetitive mild TBI. ${ }^{2,6,13 \text {, }}$ 14,18,23,38,43,48,76,92,101,109 Most studies have used rodent models, although some have investigated repetitive injury in pigs. DeFord et al. ${ }^{18}$ showed that compared with a single episode of mild TBI, repeat injury was associated with impairments in complex spatial learning and cognitive impairment, without overt cell death in the cortex or hippocampus, or BBB compromise. In this study, the authors characterized the head injury as mild by neurological assessment. The latency to right itself and latency to orient to a novel object within an open field (orientation to place) following each injury or sham injury was recorded. Mice were considered oriented to place when stable posture and at least 2 of the following criteria were observed: 1) remained alert for 10 seconds without losing consciousness; 2) attended to the novel object within the open field by sniffing or touching it with forepaws; and 3) demonstrated exploratory behavior by standing up steadily on hind legs to investigate outside the open field. ${ }^{18}$ Kanayama et al. ${ }^{37}$ demonstrated that repetitive mild TBI caused changes in cortical and hippocampal cytoskeletal proteins, whereas single injury did not. The authors in this study defined the magnitude of "sub-threshold brain injury" that did not induce brain tissue damage by a single hit, and used this magnitude of head impact for mild TBI studies. Laurer et al. ${ }^{43}$ showed that a second injury induces both local and regional changes in the cerebral cortex. On the basis of their results, the authors suggested that the brain has an increased vulnerability to a second traumatic insult for at least 24 hours following an initial episode of mild brain trauma. From a behavioral standpoint, the magnitude of mild trauma in this study caused a transient motor deficit following a single hit, as measured on motor neurological score, which resolved by 1 week after injury. This motor deficit was much more pronounced and protracted in the repetitive head injury group. Interestingly, in this model of repetitive injury there were no differences in cognitive testing at any time point in both the single and repetitive mild TBI groups. ${ }^{43}$ Another study from this same group used microtubule-associated protein-2 staining techniques to demonstrate that local and remote injury were significantly greater if they occurred in a shorter time window following the initial injury in mice that were observed to exhibit minimal behavioral response following head impact. ${ }^{48}$ Some of these studies have reported evidence of CNS injury despite no overt behavioral deficits, consistent with subconcussive injury. ${ }^{94}$

A few studies have found increases in cellular markers associated with Alzheimer disease after repeated mild injuries. ${ }^{13,37,101}$ For example, Kanayama et al. ${ }^{37}$ showed an increase in tau immunoreactivity in neurons following multiple injuries. Uryu et al. ${ }^{101}$ and Conte et al. ${ }^{13}$ used a transgenic mouse model of Alzheimer disease-like amy- loidosis, and demonstrated that amyloid levels and deposits increased in the brain after repeated injuries, but not after a single insult. Yoshiyama et al. ${ }^{109}$ used the same transgenic mouse model and analyzed the effects of 4 injuries given per day, once a week, for a period of 4 weeks, in an attempt to simulate dementia pugilistica. After 9 months, only 1 mouse demonstrated pathology consistent with this syndrome. Although the findings were not significant and more work is warranted, such studies suggest that repetitive head injury may be implicated in the development of chronic neurodegenerative disease.

There is a spectrum of neurological sequelae that are likely related to repetitive concussive and subconcussive head injury, including postconcussion syndrome, prolonged postconcussion syndrome, posttraumatic stress disorder, mild cognitive impairment, chronic traumatic encephalopathy, and dementia pugilistica. Likely related to recent increased public awareness of the possible untoward effects of repetitive head injury on athletes and soldiers, there has been a recent surge of data in this field, particularly regarding chronic traumatic encephalopathy. Initially described by Omalu et al. in 2005, ${ }^{69}$ chronic traumatic encephalopathy is defined as a progressive neurodegenerative syndrome caused by episodic and repetitive blunt force impacts to the head and transfer of acceleration-deceleration forces to the brain. Chronic traumatic encephalopathy usually presents clinically after a prolonged latent period as a composite syndrome of mood disorders, neuropsychiatric disturbance, and cognitive impairment. Gross examination of the brain reveals normal findings and fails to disclose any area of remote injury, infarction, or atrophy. Direct microscopic brain tissue analysis reveals neuronal loss and hyperphosphorylated tau protein deposits in topographic neurofibrillary tangles and neuritic threads, usually without amyloid plaques, involving various areas of the neocortex and subcortical region, basal ganglia, and brainstem. Such emerging necropsy data has highlighted the importance of subconcussion in the development of neurological injury; however, data are limited to postmortem analysis and at present there is no animal model of chronic traumatic encephalopathy that has been described in the literature. Generally, it takes years before the onset of symptoms of neurodegenerative disorders after an individual has experienced a TBI, and therefore it requires an extremely long time to gather this type of epidemiological data from the human population. ${ }^{104}$ Thus, an experimental animal model could truly help decipher the mechanisms by which chronic traumatic encephalopathy, as well as any of the other neurological sequelae such as postconcussion syndrome or mild cognitive impairment, may be triggered by repetitive brain injury.

\section{Future Directions}

Much of what we know regarding the pathophysiology of concussion is gleaned from animal work in more moderate and severe models of TBI. There has been concern over how well prior animal studies have modeled concussion. Injury models such as controlled cortical impact and fluid percussion injury have traditionally involved surgery and injury directly upon the exposed 
brain. Animal choice also presents its challenges. Rodent models allow for genetic manipulation and are typically used in most animal studies for ease and cost; however, the brain anatomy of rodents is quite different than the anatomy studied in larger animal models such as the rabbit, sheep, pig, or nonhuman primate models, and this may affect the injury patterns observed. Additionally, these models have used anesthesia during the delivery of injury, which could confound the observed pathophysiology as well as make it difficult to ascertain any subsequent periods of unconsciousness. Newer models have been developed however, that have adapted these other methods in an attempt to lessen the injury and model mild TBI more effectively. ${ }^{41,58,61,62,101,109}$ Another difficult challenge in modeling concussion has been defining and quantifying "mild TBI" for the purposes of animal modeling. The definition and perception of concussion has changed significantly over the last few years, let alone the last decade. In addition, the variable clinical nature with which each concussion presents makes 1 exact animal model not likely feasible.

In an effort to remain clinically applicable, experimental models should likely continue to use minimally invasive methods and those that do not require a craniotomy, such as weight drop models. Models must also be administered at a level that produces minimal, or preferably no fatality. Studies should be careful to clearly characterize how they define concussion within the context of their animal model with regard to behavioral response to injury. Research should also begin to focus on the emerging concept of subconcussion and its potential neurological effects. In addition to varying the injury severity, further research will be needed to investigate the effect of different interinjury intervals. Consideration will need to be given to the animal of study, as well as choosing appropriate comparison groups and proper end points for analysis. In addition, studies investigating the long-term effects (many months) following injury will be necessary to further elucidate the process of posttraumatic neurodegeneration.

As we further investigate the pathophysiological cascades underlying concussion, particularly repetitive head injury, several points are worth considering. Repetitive injury studies should attempt to evaluate cognitive function, for example using the Morris water maze test, as well as other measures of behavior observed clinically in the postconcussive setting. Pathophysiological mechanisms underlying these behavioral deficits should be pursued, as correlates could pave the way for novel translational treatment approaches. Toward the pursuit of translational treatments, in addition to trying to prevent cells from dying following repetitive injuries, it will be important to learn how to restore normal cellular physiology after head impacts. Combining studies at the cellular and behavioral levels is essential, and one area of interest will be the evaluation of the effects of repetitive TBI on both cortical and hippocampal synaptic plasticity. ${ }^{104}$

Shear strain and tissue deformation caused by rotational acceleration after a closed head injury can result in diffuse axonal damage, and concussion can be viewed as residing at the very mild end of the diffuse axonal injury spectrum. ${ }^{4,44,51}$ Typically, diffuse axonal injury presents histologically with microscopic axonal damage including myelin loss, axonal degeneration, and/or axonal swellings, as observed in much of the bench work previously discussed. These changes, however, are difficult to detect with traditional neuroimaging techniques. ${ }^{1,24,51,72,74,95} \mathrm{Al}$ though there are a number of publications evaluating the sensitivity of MRI in mild TBI, ${ }^{19,31,35,46,103}$ no study has addressed the role of MRI in the management of sportsrelated concussion, which may partly explain the absence of guidelines for the use of MRI as a routine tool in the investigation of concussion. ${ }^{17}$ Additionally, the overall availability of MRI machines and costs may limit its routine use. Another important point of consideration that has been raised in several recent reviews ${ }^{51,59}$ is that standard structural MRI does not correlate well with the number of self-reported postconcussive symptoms, performance on neuropsychological tests, or long-term outcome. ${ }^{35,45,67,86}$

Yet MRI may still play a role in the workup of the athlete with a head injury, and more importantly, could provide additional insight regarding the structural injury underlying concussion and subconcussion. Newer advanced structural MRI techniques include susceptibilityweighted imaging, diffusion-weighted imaging/apparent diffusion coefficient mapping, quantitative MRI techniques (such as voxel-based morphometry and brain segmentation), diffusion tensor imaging, and high-density fiber tracking. Additionally, advanced functional imaging can possibly supplement behavioral and structural imaging techniques by aiding in the evaluation of the pathophysiological and functional sequelae of concussion; ${ }^{51}$ such methods include functional MRI and magnetic resonance spectroscopy. At present, most of these advanced imaging modalities are used primarily as research tools in the area of concussion and TBI in general. The analysis of these advanced neuroimaging techniques requires considerable expertise, both in the reconstruction and in the interpretation of the data. There is also a need for standardization from one study to another.

Although imaging sequences such as diffusion tensor imaging and functional MRI are being used more commonly, their use as a regular tool in the diagnosis and management of concussion in adults and children remains to be seen. Some of the emerging data appear to corroborate some of the laboratory evidence suggesting that there may be a structural component to the injury (axonal injury observed in diffusion tensor imaging studies), 5,29,67 as well as a functional/metabolic component (observed in functional MRI studies). ${ }^{11,100}$ The studies thus far have suggested that these two modalities in particular could be used in future research to evaluate treatment efficacy, given their enhanced sensitivity to alterations in the brain. ${ }^{5,11}$, 16,29,49,67,91,100,110 Future studies may demonstrate that such advanced imaging modalities could potentially direct rehabilitation after concussion and possibly aid in the decision of determining when it is safe for an athlete to return to play, ${ }^{56}$ although there is no evidence at the present time to support those conclusions.

\section{Conclusions}

Most scientific studies have focused on moderate 
and severe TBI, but concussive and subconcussive head injuries affect more people, occur more frequently, and are an increasingly important silent epidemic because younger patients suffer more mild TBI as a consequence of sports activities and military experience. The science behind concussion continues to evolve at a rapid pace. As we learn more about the pathophysiology and biophysics underlying concussion and repetitive head injury, further questions arise. As this arena of TBI research continues to evolve, it will be imperative that models of repetitive injury replicate injuries in humans as closely as possible. It will also be important to appropriately model concussive episodes and even lower-level injuries (such as subconcussion) as we search for translational treatment approaches as well as answers to how mild TBI results in the observed spectrum of neurological sequelae, particularly chronic neurodegenerative disease.

\section{Disclosure}

The authors report no conflict of interest concerning the materials or methods used in this study or the findings specified in this paper.

Author contributions to the study and manuscript preparation include the following. Conception and design: Petraglia, Bailes. Acquisition of data: Petraglia, Dashnaw. Analysis and interpretation of data: Petraglia, Dashnaw. Drafting the article: Dashnaw. Critically revising the article: Petraglia, Dashnaw. Reviewed submitted version of manuscript: all authors. Approved the final version of the manuscript on behalf of all authors: Petraglia. Study supervision: Bailes.

\section{References}

1. Adams JH, Doyle D, Ford I, Gennarelli TA, Graham DI, McLellan DR: Diffuse axonal injury in head injury: definition, diagnosis and grading. Histopathology 15:49-59, 1989

2. Allen GV, Gerami D, Esser MJ: Conditioning effects of repetitive mild neurotrauma on motor function in an animal model of focal brain injury. Neuroscience 99:93-105, 2000

3. Andrew RD: Seizure and acute osmotic change: clinical and neurophysiological aspects. J Neurol Sci 101:7-18, 1991

4. Bayly PV, Cohen TS, Leister EP, Ajo D, Leuthardt EC, Genin GM: Deformation of the human brain induced by mild acceleration. J Neurotrauma 22:845-856, 2005

5. Bazarian JJ, Zhu T, Blyth B, Borrino A, Zhong J: Subjectspecific changes in brain white matter on diffusion tensor imaging after sports-related concussion. Magn Reson Imaging 30:171-180, 2012

6. Bennett RE, Mac Donald CL, Brody DL: Diffusion tensor imaging detects axonal injury in a mouse model of repetitive closed-skull traumatic brain injury. Neurosci Lett 513:160165,2012

7. Bergsneider M, Hovda DA, Shalmon E, Kelly DF, Vespa PM, Martin NA, et al: Cerebral hyperglycolysis following severe traumatic brain injury in humans: a positron emission tomography study. J Neurosurg 86:241-251, 1997

8. Blaylock RL, Maroon J: Immunoexcitotoxicity as a central mechanism in chronic traumatic encephalopathy-a unifying hypothesis. Surg Neurol Int 2:107, 2011

9. Block ML, Zecca L, Hong JS: Microglia-mediated neurotoxicity: uncovering the molecular mechanisms. Nat Rev Neurosci 8:57-69, 2007

10. Blumbergs PC, Scott G, Manavis J, Wainwright H, Simpson DA, McLean AJ: Staining of amyloid precursor protein to study axonal damage in mild head injury. Lancet 344:10551056, 1994

11. Breedlove EL, Robinson M, Talavage TM, Morigaki KE, Yoruk U, O'Keefe K, et al: Biomechanical correlates of symptom- atic and asymptomatic neurophysiological impairment in high school football. J Biomech 45:1265-1272, 2012

12. Broglio SP, Eckner JT, Martini D, Sosnoff JJ, Kutcher JS, Randolph C: Cumulative head impact burden in high school football. J Neurotrauma 28:2069-2078, 2011

13. Conte V, Uryu K, Fujimoto S, Yao Y, Rokach J, Longhi L, et al: Vitamin $\mathrm{E}$ reduces amyloidosis and improves cognitive function in $\mathrm{Tg} 2576$ mice following repetitive concussive brain injury. J Neurochem 90:758-764, 2004

14. Creeley CE, Wozniak DF, Bayly PV, Olney JW, Lewis LM: Multiple episodes of mild traumatic brain injury result in impaired cognitive performance in mice. Acad Emerg Med 11:809-819, 2004

15. Crisco JJ, Fiore R, Beckwith JG, Chu JJ, Brolinson PG, Duma $\mathrm{S}$, et al: Frequency and location of head impact exposures in individual collegiate football players. J Athl Train 45:549559,2010

16. Cubon VA, Putukian M, Boyer C, Dettwiler A: A diffusion tensor imaging study on the white matter skeleton in individuals with sports-related concussion. J Neurotrauma 28:189201, 2011

17. Davis GA, Iverson GL, Guskiewicz KM, Ptito A, Johnston KM: Contributions of neuroimaging, balance testing, electrophysiology and blood markers to the assessment of sport-related concussion. Br J Sports Med 43 (Suppl 1):i36-i45, 2009

18. DeFord SM, Wilson MS, Rice AC, Clausen T, Rice LK, Barabnova A, et al: Repeated mild brain injuries result in cognitive impairment in B6C3F1 mice. J Neurotrauma 19:427-438, 2002

19. Doezema D, King JN, Tandberg D, Espinosa MC, Orrison WW: Magnetic resonance imaging in minor head injury. Ann Emerg Med 20:1281-1285, 1991

20. Engel S, Wehner HD, Meyermann R: Expression of microglial markers in the human CNS after closed head injury. Acta Neurochir Suppl 66:89-95, 1996

21. Faden AI, Demediuk P, Panter SS, Vink R: The role of excitatory amino acids and NMDA receptors in traumatic brain injury. Science 244:798-800, 1989

22. Farkas O, Lifshitz J, Povlishock JT: Mechanoporation induced by diffuse traumatic brain injury: an irreversible or reversible response to injury? J Neurosci 26:3130-3140, 2006

23. Friess SH, Ichord RN, Ralston J, Ryall K, Helfaer MA, Smith $\mathrm{C}$, et al: Repeated traumatic brain injury affects composite cognitive function in piglets. J Neurotrauma 26:1111-1121, 2009

24. Gentry LR, Godersky JC, Thompson B: MR imaging of head trauma: review of the distribution and radiopathologic features of traumatic lesions. AJR Am J Roentgenol 150:663672,1988

25. Ghirnikar RS, Lee YL, Eng LF: Inflammation in traumatic brain injury: role of cytokines and chemokines. Neurochem Res 23:329-340, 1998

26. Ginsberg MD, Zhao W, Alonso OF, Loor-Estades JY, Dietrich WD, Busto R: Uncoupling of local cerebral glucose metabolism and blood flow after acute fluid-percussion injury in rats. Am J Physiol 272:H2859-H2868, 1997

27. Guskiewicz KM, Mihalik JP, Shankar V, Marshall SW, Crowell DH, Oliaro SM, et al: Measurement of head impacts in collegiate football players: relationship between head impact biomechanics and acute clinical outcome after concussion. Neurosurgery 61:1244-1253, 2007

28. Gysland SM, Mihalik JP, Register-Mihalik JK, Trulock SC, Shields EW, Guskiewicz KM: The relationship between subconcussive impacts and concussion history on clinical measures of neurologic function in collegiate football players. Ann Biomed Eng 40:14-22, 2012

29. Henry LC, Tremblay J, Tremblay S, Lee A, Brun C, Lepore N, et al: Acute and chronic changes in diffusivity measures after sports concussion. J Neurotrauma 28:2049-2059, 2011 
30. Herman ST: Epilepsy after brain insult: targeting epileptogenesis. Neurology 59 (9 Suppl 5):S21-S26, 2002

31. Hofman PA, Stapert SZ, van Kroonenburgh MJ, Jolles J, de Kruijk J, Wilmink JT: MR imaging, single-photon emission $\mathrm{CT}$, and neurocognitive performance after mild traumatic brain injury. AJNR Am J Neuroradiol 22:441-449, 2001

32. Homsi S, Piaggio T, Croci N, Noble F, Plotkine M, MarchandLeroux C, et al: Blockade of acute microglial activation by minocycline promotes neuroprotection and reduces locomotor hyperactivity after closed head injury in mice: a twelveweek follow-up study. J Neurotrauma 27:911-921, 2010

33. Hootman JM, Dick R, Agel J: Epidemiology of collegiate injuries for 15 sports: summary and recommendations for injury prevention initiatives. J Athl Train 42:311-319, 2007

34. Hovda DA, Yoshino A, Kawamata T, Katayama Y, Becker DP: Diffuse prolonged depression of cerebral oxidative metabolism following concussive brain injury in the rat: a cytochrome oxidase histochemistry study. Brain Res 567:1-10, 1991

35. Hughes DG, Jackson A, Mason DL, Berry E, Hollis S, Yates DW: Abnormalities on magnetic resonance imaging seen acutely following mild traumatic brain injury: correlation with neuropsychological tests and delayed recovery. Neuroradiology 46:550-558, 2004

36. Kalimo H, Rehncrona S, Söderfeldt B: The role of lactic acidosis in the ischemic nerve cell injury. Acta Neuropathol Suppl 7:20-22, 1981

37. Kanayama G, Takeda M, Niigawa H, Ikura Y, Tamii H, Taniguchi N, et al: The effects of repetitive mild brain injury on cytoskeletal protein and behavior. Methods Find Exp Clin Pharmacol 18:105-115, 1996

38. Kane MJ, Angoa-Pérez M, Briggs DI, Viano DC, Kreipke CW, Kuhn DM: A mouse model of human repetitive mild traumatic brain injury. J Neurosci Methods 203:41-49, 2012

39. Katayama Y, Becker DP, Tamura T, Hovda DA: Massive increases in extracellular potassium and the indiscriminate release of glutamate following concussive brain injury. J Neurosurg 73:889-900, 1990

40. Kawamata T, Katayama Y, Hovda DA, Yoshino A, Becker DP: Administration of excitatory amino acid antagonists via microdialysis attenuates the increase in glucose utilization seen following concussive brain injury. J Cereb Blood Flow Metab 12:12-24, 1992

41. Khuman J, Meehan WP III, Zhu X, Qiu J, Hoffmann U, Zhang $\mathrm{J}$, et al: Tumor necrosis factor alpha and Fas receptor contribute to cognitive deficits independent of cell death after concussive traumatic brain injury in mice. J Cereb Blood Flow Metab 31:778-789, 2011

42. Korn A, Golan H, Melamed I, Pascual-Marqui R, Friedman A: Focal cortical dysfunction and blood-brain barrier disruption in patients with postconcussion syndrome. J Clin Neurophysiol 22:1-9, 2005

43. Laurer HL, Bareyre FM, Lee VM, Trojanowski JQ, Longhi L, Hoover R, et al: Mild head injury increasing the brain's vulnerability to a second concussive impact. J Neurosurg 95:859-870, 2001

44. Le TH, Gean AD: Neuroimaging of traumatic brain injury. Mt Sinai J Med 76:145-162, 2009

45. Lee H, Wintermark M, Gean AD, Ghajar J, Manley GT, Mukherjee P: Focal lesions in acute mild traumatic brain injury and neurocognitive outcome: CT versus 3T MRI. J Neurotrauma 25:1049-1056, 2008

46. Lewine JD, Davis JT, Bigler ED, Thoma R, Hill D, Funke M, et al: Objective documentation of traumatic brain injury subsequent to mild head trauma: multimodal brain imaging with MEG, SPECT, and MRI. J Head Trauma Rehabil 22:141155,2007

47. Lifshitz J, Sullivan PG, Hovda DA, Wieloch T, McIntosh TK: Mitochondrial damage and dysfunction in traumatic brain injury. Mitochondrion 4:705-713, 2004
48. Longhi L, Saatman KE, Fujimoto S, Raghupathi R, Meaney DF, Davis J, et al: Temporal window of vulnerability to repetitive experimental concussive brain injury. Neurosurgery 56:364-374, 2005

49. Luther N, Niogi S, Kutner K, Rodeo S, Shetty T, Warren R, et al: 143 Diffusion tensor and susceptibility-weighted imaging in concussion assessment of National Football League players. Neurosurgery 71:E558, 2012

50. Martin NA, Patwardhan RV, Alexander MJ, Africk CZ, Lee $\mathrm{JH}$, Shalmon E, et al: Characterization of cerebral hemodynamic phases following severe head trauma: hypoperfusion, hyperemia, and vasospasm. J Neurosurg 87:9-19, 1997

51. Maruta J, Lee SW, Jacobs EF, Ghajar J: A unified science of concussion. Ann N Y Acad Sci 1208:58-66, 2010

52. Masuzawa H, Nadamura N, Hirakawa K, Sano K, Matsuno M: Experimental head injury \& concussion in monkey using pure linear acceleration impact. Neurol Med Chir (Tokyo) 16:77-90, 1976

53. Maugans TA, Farley C, Altaye M, Leach J, Cecil KM: Pediatric sports-related concussion produces cerebral blood flow alterations. Pediatrics 129:28-37, 2012

54. Maxwell WL, Graham DI: Loss of axonal microtubules and neurofilaments after stretch-injury to guinea pig optic nerve fibers. J Neurotrauma 14:603-614, 1997

55. McCrory PR, Berkovic SF: Video analysis of acute motor and convulsive manifestations in sport-related concussion. Neurology 54:1488-1491, 2000

56. McCullough BJ, Jarvik JG: Diagnosis of concussion: the role of imaging now and in the future. Phys Med Rehabil Clin N Am 22:635-652, viii, 2011

57. Meehan WP III, Bachur RG: Sport-related concussion. Pediatrics 123:114-123, 2009

58. Meehan WP III, Zhang J, Mannix R, Whalen MJ: Increasing recovery time between injuries improves cognitive outcome after repetitive mild concussive brain injuries in mice. Neurosurgery 71:885-892, 2012

59. Mendez CV, Hurley RA, Lassonde M, Zhang L, Taber KH: Mild traumatic brain injury: neuroimaging of sports-related concussion. J Neuropsychiatry Clin Neurosci 17:297-303, 2005

60. Miller JR, Adamson GJ, Pink MM, Sweet JC: Comparison of preseason, midseason, and postseason neurocognitive scores in uninjured collegiate football players. Am J Sports Med 35: 1284-1288, 2007

61. Mills JD, Bailes JE, Sedney CL, Hutchins H, Sears B: Omega-3 fatty acid supplementation and reduction of traumatic axonal injury in a rodent head injury model. Laboratory investigation. J Neurosurg 114:77-84, 2011

62. Mills JD, Hadley K, Bailes JE: Dietary supplementation with the omega-3 fatty acid docosahexaenoic acid in traumatic brain injury. Neurosurgery 68:474-481, 2011

63. Muir JK, Boerschel M, Ellis EF: Continuous monitoring of posttraumatic cerebral blood flow using laser-Doppler flowmetry. J Neurotrauma 9:355-362, 1992

64. Nakajima Y, Horiuchi Y, Kamata H, Yukawa M, Kuwabara M, Tsubokawa T: Distinct time courses of secondary brain damage in the hippocampus following brain concussion and contusion in rats. Tohoku J Exp Med 221:229-235, 2010

65. Nakamura Y, Takeda M, Angelides KJ, Tanaka T, Tada K, Nishimura T: Effect of phosphorylation on $68 \mathrm{KDa}$ neurofilament subunit protein assembly by the cyclic AMP dependent protein kinase in vitro. Biochem Biophys Res Commun 169: 744-750, 1990

66. Nilsson P, Ronne-Engström E, Flink R, Ungerstedt U, Carlson $\mathrm{H}$, Hillered L: Epileptic seizure activity in the acute phase following cortical impact trauma in rat. Brain Res 637:227-232, 1994

67. Niogi SN, Mukherjee P, Ghajar J, Johnson C, Kolster RA, Sarkar R, et al: Extent of microstructural white matter injury 
in postconcussive syndrome correlates with impaired cognitive reaction time: a $3 \mathrm{~T}$ diffusion tensor imaging study of mild traumatic brain injury. AJNR Am J Neuroradiol 29: 967-973, 2008

68. Nixon RA: The regulation of neurofilament protein dynamics by phosphorylation: clues to neurofibrillary pathobiology. Brain Pathol 3:29-38, 1993

69. Omalu BI, DeKosky ST, Minster RL, Kamboh MI, Hamilton RL, Wecht CH: Chronic traumatic encephalopathy in a National Football League player. Neurosurgery 57:128-134, 2005

70. Ommaya AK, Corrao P, Letcher FS: Head injury in the chimpanzee. 1. Biodynamics of traumatic unconsciousness. J Neurosurg 39:152-166, 1973

71. Ommaya AK, Hirsch AE: Tolerances for cerebral concussion from head impact and whiplash in primates. J Biomech 4:13-21, 1971

72. Oppenheimer DR: Microscopic lesions in the brain following head injury. J Neurol Neurosurg Psychiatry 31:299-306, 1968

73. Pellman EJ, Viano DC, Tucker AM, Casson IR, Waeckerle JF: Concussion in professional football: reconstruction of game impacts and injuries. Neurosurgery 53:799-814, 2003

74. Povlishock JT, Becker DP, Cheng CL, Vaughan GW: Axonal change in minor head injury. J Neuropathol Exp Neurol 42:225-242, 1983

75. Povlishock JT, Christman CW: The pathobiology of traumatically induced axonal injury in animals and humans: a review of current thoughts. J Neurotrauma 12:555-564, 1995

76. Raghupathi R, Mehr MF, Helfaer MA, Margulies SS: Traumatic axonal injury is exacerbated following repetitive closed head injury in the neonatal pig. J Neurotrauma 21:307-316, 2004

77. Rancan M, Otto VI, Hans VH, Gerlach I, Jork R, Trentz O, et al: Upregulation of ICAM-1 and MCP-1 but not of MIP-2 and sensorimotor deficit in response to traumatic axonal injury in rats. J Neurosci Res 63:438-446, 2001

78. Ransohoff RM, Perry VH: Microglial physiology: unique stimuli, specialized responses. Annu Rev Immunol 27:119145,2009

79. Rhodes JKJ, Sharkey J, Andrews PJD: The temporal expression, cellular localization, and inhibition of the chemokines MIP-2 and MCP-1 after traumatic brain injury in the rat. $\mathbf{J}$ Neurotrauma 26:507-525, 2009

80. Robertson CL, Saraswati M, Fiskum G: Mitochondrial dysfunction early after traumatic brain injury in immature rats. $\mathbf{J}$ Neurochem 101:1248-1257, 2007

81. Rosen AS, Andrew RD: Osmotic effects upon excitability in rat neocortical slices. Neuroscience 38:579-590, 1990

82. Rowson S, Duma SM, Beckwith JG, Chu JJ, Greenwald RM, Crisco JJ, et al: Rotational head kinematics in football impacts: an injury risk function for concussion. Ann Biomed Eng 40:1-13, 2012

83. Saatman KE, Abai B, Grosvenor A, Vorwerk CK, Smith DH, Meaney DF: Traumatic axonal injury results in biphasic calpain activation and retrograde transport impairment in mice. J Cereb Blood Flow Metab 23:34-42, 2003

84. Saly V, Andrew RD: CA3 neuron excitation and epileptiform discharge are sensitive to osmolality. J Neurophysiol 69: 2200-2208, 1993

85. Sass DJ, Corrao P, Ommaya AK: Brain motion during vibration of water immersed rhesus monkeys. J Biomech 4:331334, 1971

86. Scheid R, Walther K, Guthke T, Preul C, von Cramon DY: Cognitive sequelae of diffuse axonal injury. Arch Neurol 63: 418-424, 2006

87. Schnebel B, Gwin JT, Anderson S, Gatlin R: In vivo study of head impacts in football: a comparison of National Collegiate Athletic Association Division I versus high school impacts. Neurosurgery 60:490-496, 2007
88. Schwartzkroin PA, Baraban SC, Hochman DW: Osmolarity, ionic flux, and changes in brain excitability. Epilepsy Res 32:275-285, 1998

89. Sekino H, Nakamura N, Kanda R, Yasue M, Masuzawa H, Aoyagi N, et al: [Experimental head injury in monkeys using rotational acceleration impact (author's transl).] Neurol Med Chir (Tokyo) 20:127-136, 1980 (Jpn)

90. Shapira Y, Setton D, Artru AA, Shohami E: Blood-brain barrier permeability, cerebral edema, and neurologic function after closed head injury in rats. Anesth Analg 77:141-148, 1993

91. Shenton ME, Hamoda HM, Schneiderman JS, Bouix S, Pasternak O, Rathi Y, et al: A review of magnetic resonance imaging and diffusion tensor imaging findings in mild traumatic brain injury. Brain Imaging Behav 6:137-192, 2012

92. Shitaka Y, Tran HT, Bennett RE, Sanchez L, Levy MA, Dikranian K, et al: Repetitive closed-skull traumatic brain injury in mice causes persistent multifocal axonal injury and microglial reactivity. J Neuropathol Exp Neurol 70:551567,2011

93. Shlosberg D, Benifla M, Kaufer D, Friedman A: Blood-brain barrier breakdown as a therapeutic target in traumatic brain injury. Nat Rev Nephrol 6:393-403, 2010

94. Shultz SR, MacFabe DF, Foley KA, Taylor R, Cain DP: Subconcussive brain injury in the Long-Evans rat induces acute neuroinflammation in the absence of behavioral impairments. Behav Brain Res 229:145-152, 2012

95. Smith DH, Meaney DF, Shull WH: Diffuse axonal injury in head trauma. J Head Trauma Rehabil 18:307-316, 2003

96. Smith DW, Bailes JE, Fisher JA, Robles J, Turner RC, Mills JD: Internal jugular vein compression mitigates traumatic axonal injury in a rat model by reducing the intracranial slosh effect. Neurosurgery 70:740-746, 2012

97. Spain A, Daumas S, Lifshitz J, Rhodes J, Andrews PJD, Horsburgh K, et al: Mild fluid percussion injury in mice produces evolving selective axonal pathology and cognitive deficits relevant to human brain injury. J Neurotrauma 27: 1429-1438, 2010

98. Sternberger LA, Sternberger NH: Monoclonal antibodies distinguish phosphorylated and nonphosphorylated forms of neurofilaments in situ. Proc Natl Acad Sci U S A 80:6126-6130, 1983

99. Suwanwela C, Suwanwela N: Intracranial arterial narrowing and spasm in acute head injury. J Neurosurg 36:314-323, 1972

100. Talavage TM, Nauman E, Breedlove EL, Yoruk U, Dye AE, Morigaki K, et al: Functionally-detected cognitive impairment in high school football players without clinically-diagnosed concussion. J Neurotrauma [epub ahead of print], 2010

101. Uryu K, Laurer H, McIntosh T, Praticò D, Martinez D, Leight S, et al: Repetitive mild brain trauma accelerates Abeta deposition, lipid peroxidation, and cognitive impairment in a transgenic mouse model of Alzheimer amyloidosis. J Neurosci 22:446-454, 2002

102. Verweij BH, Muizelaar JP, Vinas FC, Peterson PL, Xiong Y, Lee CP: Mitochondrial dysfunction after experimental and human brain injury and its possible reversal with a selective N-type calcium channel antagonist (SNX-111). Neurol Res 19:334-339, 1997

103. Voller B, Benke T, Benedetto K, Schnider P, Auff E, Aichner F: Neuropsychological, MRI and EEG findings after very mild traumatic brain injury. Brain Inj 13:821-827, 1999

104. Weber JT: Experimental models of repetitive brain injuries. Prog Brain Res 161:253-261, 2007

105. Xiong Y, Gu Q, Peterson PL, Muizelaar JP, Lee CP: Mitochondrial dysfunction and calcium perturbation induced by traumatic brain injury. J Neurotrauma 14:23-34, 1997

106. Yamakami I, McIntosh TK: Effects of traumatic brain injury on regional cerebral blood flow in rats as measured with 


\section{Basic science of concussion and subconcussion}

radiolabeled microspheres. J Cereb Blood Flow Metab 9: 117-124, 1989

107. Yarnell P, Ommaya AK: Experimental cerebral concussion in the rhesus monkey. Bull N Y Acad Med 45:39-45, 1969

108. Yoshino A, Hovda DA, Kawamata T, Katayama Y, Becker DP: Dynamic changes in local cerebral glucose utilization following cerebral conclusion in rats: evidence of a hyper- and subsequent hypometabolic state. Brain Res 561:106-119, 1991

109. Yoshiyama Y, Uryu K, Higuchi M, Longhi L, Hoover R, Fujimoto S, et al: Enhanced neurofibrillary tangle formation, cerebral atrophy, and cognitive deficits induced by repetitive mild brain injury in a transgenic tauopathy mouse model. J Neurotrauma 22:1134-1141, 2005
110. Zhang K, Johnson B, Pennell D, Ray W, Sebastianelli W, Slobounov S: Are functional deficits in concussed individuals consistent with white matter structural alterations: combined FMRI \& DTI study. Exp Brain Res 204:57-70, 2010

Manuscript submitted August 15, 2012.

Accepted October 2, 2012.

Please include this information when citing this paper: DOI: 10.3171/2012.10.FOCUS12284.

Address correspondence to: Anthony L. Petraglia, M.D., Department of Neurosurgery, University of Rochester Medical Center, 601 Elmwood Avenue, Box 670, Rochester, New York 14642. email: anthony_petraglia@urmc.rochester.edu. 